\title{
Violência doméstica contra crianças e adolescentes: estudo de um programa de intervenção
}

\author{
Domestic violence against children and adolescents: \\ a supporting program study
}

Ana Maria M. Brito 1

Dirce Maria T. Zanetta 2

Rita de Cássia V. Mendonça 1

Sueli Z. P. Barison 1

Valdete A. G. Andrade 1

${ }^{1}$ Centro Regional de Atenção aos Maus Tratos na Infância, CRAMI. Av. Brigadeiro Faria Lima, 5.511, Vila Universitária, 15090-000, São José do Rio Preto SP. anamamessias@bol.com.br

2 Departamento de Epidemiologia e Saúde Coletiva da Faculdade Medicina SJRP.
Abstract This study presents general characteristcs of families in which there was the occurrence of violence against the child as well as to evaluate the results of a supporting program made by the Centro Regional de Atenção aos Maus-Tratos na Infância (CRAMI) for these families. Fifty-five families were interviewed, and a structured questionnaire was used. Among the families, the most prevalent type of violence was physical (58\%). Sixty percent of the victims were females, and the mother was the main batterer (49\%). Some factors to start committing the violence included: conflicts between the couple (58\%); the child's own characteristics (51\%) and the parent's life history (49\%). The majority of families (80\%) believes that this supporting program has provided them decreasing the intensity even interruption of the violence. At-home visits was the most useful way for the parent's compliance to the program. This supporting programs can provide these families better results as long as violence is understood in its different aspects; that is, a present symptom in the family group shaped by several difficulties such as cultural, social, economic, and of relationship among the members.

Key words Children and adolescents, Domestic violence, Violent families, Supporting programs
Resumo Este estudo apresenta características gerais de familias nas quais houve a ocorrência de violência doméstica contra crianças, e avalia os resultados de seu acompanhamento pelo Centro Regional de Atenção aos Maus-Tratos na Infância (CRAMI-Rio Preto). Foram entrevistadas cinqüenta e cinco famílias, que responderam um questionário estruturado. A forma de violência mais prevalente foi a física, presente em $58 \%$ dos casos. Sessenta por cento das vítimas são do sexo feminino, e a mãe é agressora em 49\% das situações analisadas. Os principais fatores desencadeantes da violência, identificados pelas famílias, são conflitos do casal (58\%), características próprias da criança (51\%) e histórico de vida dos pais (49\%). A maioria das famílias (80\%) acredita que a intervenção proporcionou interrupção ou diminuição na intensidade da violência e a forma de acompanhamento que mais houve adesão dos pais foi por meio das visitas domiciliares. Observa-se que a intervenção junto dessas famílias pode ter resultados satisfatórios, desde que a violência possa ser compreendida em seus vários aspectos, ou seja, um sintoma presente no grupo familiar modelado por dificuldades de diferentes naturezas: cultural, social, econômica e das relações interpessoais.

Palavras-chave Crianças e adolescentes, Violência doméstica, Famílias violentas, Intervenção 


\section{Introdução}

No Brasil, a violência é apontada, desde a década de 1970, como uma das principais causas de morbi-mortalidade, despertando, no setor saúde, uma grande preocupação com essa temática que, progressivamente, deixa de ser considerada um problema exclusivo da área social e jurídica para ser também incluída no universo da saúde pública.

Para alguns pesquisadores da área de saúde mesmo com a falta de integração e escassez de dados é possível inferir que as várias modalidades de violência ocorridas no ambiente familiar podem ser responsáveis por grande parte dos atos violentos que compõem o índice de morbi-mortalidade (Minayo, 1994). Apesar de ser um fenômeno que ocorre desde a Antigüidade, a violência doméstica, em especial aquela dirigida à criança e ao adolescente, passou a ser mais discutida no meio científico a partir dos anos 80 (Santos, 1987; Azevedo \& Guerra, 1988; 1989; 1995; Marques, 1986; Minayo, 1993; Saffioti, 1997). É também nessa década que começam a surgir os primeiros programas específicos para atendimento dessa problemática, previsto no artigo 87, inciso III, lei 8.069/90 - Estatuto da Criança e Adolescente, como o Centro Regional de Atenção aos Maus-Tratos na Infância - São José do Rio Preto implantado em outubro de 1988, conforme modelo do CRAMI - Campinas, criado em 1985.

Desde então, o conhecimento sobre essa forma de violência vem sendo ampliado e sua gravidade reconhecida, ainda que os dados globais sobre sua magnitude não estejam devidamente dimensionados. No Brasil, a padronização para registrar situações de violência familiar é fragmentada, o que provoca prejuízo para uma rotina clara e eficaz, ocasionando deficiências nos procedimentos a serem seguidos pelos profissionais e instituições. Além disso, há carência de políticas públicas eficazes que viabilizem a criação e, principalmente, a manutenção de programas preventivos e de tratamento, necessários para promover o aprimoramento e evolução de técnicas eficazes no enfrentamento dessa problemática.

Atualmente observam-se alguns avanços na área da saúde, educação e segurança pública, o que provavelmente desencadeará novos processos e possibilidades de ações. No ano de 2000, o governador do Estado de São Paulo criou e promulgou a lei 10.498 , de 5 de janeiro de 2000 , que dispõe sobre a obrigatoriedade da notificação dos casos em que haja suspeita ou confirmação de maus-tratos contra criança e adolescente para os estabelecimentos de Educação, Saúde e Segurança Pública. Em consonância com esta determinação, o Ministério da Saúde publicou, no Diário Oficial da União, a portaria 1968, de 25 de outubro de 2001, que estabelece a obrigatoriedade da Notificação Compulsória para os profissionais dos estabelecimentos do Sistema Único de Saúde (SUS), criando a Ficha de Notificação Compulsória de Maus-Tratos Contra Criança e Adolescente, fundamentadas nos artigos 13 e 245 do Estatuto da Criança e Adolescente (Ministério da Saúde, 2001).

Essas ações federais e estaduais são instrumentos fundamentais para o processo de conhecimento e visibilidade desse problema nos municípios, Estados e país, colaborando com trabalhos de pesquisa e, conseqüentemente, proporcionando melhoria na qualidade dos programas de intervenção.

A proposta de intervenção realizada pelo CRAMI - São José do Rio Preto tem como objetivo fortalecer os laços afetivos e favorecer transformações positivas nas relações familiares, criando e melhorando as condições de cuidado dos adultos responsáveis pela criança.

O trabalho com as famílias é desenvolvido por psicólogos e assistentes sociais, por atividades como:

- acompanhamento em visitas domiciliares, semanais, quinzenais ou mensais, conforme necessário;

- atendimento psicoterapêutico semanal para adultos, crianças e adolescentes, em sessões individuais ou em grupos, conforme indicação; encontros semanais em grupo de reflexão com pais, realizado em dois bairros que apresentam grande incidência de notificações de violência doméstica;

- palestras, sensibilização e comitês, voltados a profissionais das diversas áreas de atendimento e proteção à criança e ao adolescente;

- cartilhas elaboradas para orientação, acerca do fenômeno e suas implicações, divididas em duas formas: para pais e leigos e para técnicos das áreas de atendimento à criança/adolescente.

O presente estudo se propõe a analisar as formas de intervenção e suas conseqüências sobre as famílias atendidas.

Os objetivos deste estudo são: conhecer as características gerais da família, da criança que sofreu violência e da pessoa responsável pelo ato violento; descrever, segundo a avaliação das 
famílias, os fatores desencadeantes da violência; analisar a forma como as famílias receberam o tratamento oferecido pela instituição; avaliar o impacto da intervenção na intensidade da violência familiar.

\section{Métodos}

Este estudo, de natureza descritiva, analisa características gerais de famílias atendidas pelo CRAMI, vítimas de violência contra filhos, e a repercussão que o acompanhamento realizado provocou na organização dessas famílias.

O instrumento utilizado para coletar os dados foi um questionário elaborado pelos pesquisadores, com base em bibliografia específica e na experiência de trabalho com as famílias. $\mathrm{O}$ questionário foi subdividido em seis partes, assim denominadas: I) Identificação; II) Notificação; III) Órgãos de Proteção; IV) Intervenção do CRAMI; V) Encaminhamentos; VI) Fatores Desencadeantes.

A aplicação desse instrumento foi feita por cinco entrevistadores: três assistentes sociais e dois psicólogos, previamente treinados para que as dúvidas fossem esclarecidas e houvesse homogeneidade na aplicação dos questionários.

As famílias foram abordadas por telefone ou em seus domicílios, por um entrevistador que informava ao entrevistado o objetivo e a duração aproximada para sua realização e solicitava sua participação voluntária no processo, garantindo-lhes anonimato e sigilo. Havendo concordância em participar do estudo, a entrevista era realizada naquele momento ou agendada para outro dia, dependendo da disponibilidade do entrevistado, no caso um responsável legal pela criança.

Da população inicial de 84 famílias que estavam em acompanhamento no CRAMI, na ocasião da pesquisa, 55 responderam o questionário. As 29 restantes não participaram da pesquisa devido a diferentes circunstâncias: 12 não foram localizadas em função de mudança de endereço; com 15 famílias foi realizada alguma forma de contato, mas não chegaram a responder o questionário, sendo que nove não compareceram no horário agendado, após três novas tentativas de contato; um desmarcou por mais de três vezes; em um caso, o responsável legal não tinha as informações para responder o questionário, porque os pais estavam na prisão; em quatro casos, deixamos recado na residência por três vezes e não retornaram conta- to. Em dois casos houve recusa para responder o questionário.

O projeto de pesquisa foi previamente submetido à apreciação do Comitê de Ética e Pesquisa da Faculdade de Medicina de São José do Rio Preto - FAMERP, aprovada em 12 de novembro de 2001, sob no 108/2001.

\section{Resultados}

As modalidades de violência doméstica, cometidas contra crianças e adolescentes, são classificadas em: violência física, violência psicológica, negligência e violência sexual. Essas modalidades podem ocorrer na forma pura, quando se trata de uma única modalidade de violência, ou associada, quando em um mesmo caso são identificadas duas ou mais modalidades.

A violência física é a mais notificada, presente em 58\% dos casos. É seguida pela negligência e violência psicológica, cada uma representando $34,5 \%$ e, por último, a violência sexual aparece em $29 \%$ das notificações. Na forma pura, a violência psicológica é a menos identificada, $4 \%$, e cada uma das demais modalidades representa cerca de $14 \%$.

A violência física associada à psicológica é a que apresenta maior freqüência, representando $20 \%$ dos casos. A violência física associada à negligência está presente em $10,9 \%$ e a violência sexual, associada à física, aparece em 7,2\% das notificações.

As crianças do sexo feminino são submetidas a situações de violência com mais freqüência que as do sexo masculino, representando $60 \%$ do total de notificações. Porém, quando são consideradas as modalidades de violência, observa-se uma variação quanto ao sexo da criança vitimizada. Na violência física e violência psicológica, existe certo equilíbrio na distribuição das notificações entre os sexos, com leve tendência do sexo feminino apresentar maior freqüência. Uma diferença significativa entre os sexos aparece, quando a violência sofrida se refere à negligência $(\mathrm{p}=0,010)$, e à violência sexual $(\mathrm{p}=0,007)$. Na primeira é o sexo masculino que apresenta o maior número de notificações, a razão aproximada é 1:2. Ao contrário, na violência sexual, é o sexo feminino que apresenta maior índice de notificações, em razão de 1:7.

Ainda com relação ao sexo das crianças, foram observadas variações conforme a idade. Nesse sentido, é interessante que até os sete 
anos de idade é o sexo masculino quem sofre mais violência. A partir dos sete, ocorre uma inversão desses valores, e são as crianças do sexo feminino as mais atingidas. A faixa etária que mais sofre violência está entre os sete e onze anos, em um total de 15 crianças, sendo que as meninas representam $75 \%$.

É a mãe quem está fisicamente mais próxima da criança; em $78 \%$ dos casos ela reside com a criança. Já o pai reside com a mesma em $34 \%$ das situações notificadas, menos da metade, quando comparado com a mãe. Dos 55 casos notificados, a mãe é agressora em $49 \%$ e o pai em $40 \%$. As medidas de proteção (afastamento do agressor da residência sem direito a visita ou afastamento do agressor da residência com direito a visita e/ou acompanhamento do agressor em tratamento compulsório ocorreram em 27 casos. Quando o pai é o agressor $(n=22)$, houve medidas de proteção em $40 \%$ dos casos. Já se a mãe foi a agressora $(n=27)$, as medidas de proteção ocorreram em menor freqüência $18,5 \%$ dos casos.

A tabela 1 ilustra a variação das modalidades de violência cometidas pelo pai e pela mãe. Observamos que a negligência, quando não associada a outras modalidades de violência, prevalece quando a mãe é agressora. A violência sexual associada ou não a outras modalidades só aparece quando o pai é agressor.

Quanto aos fatores desencadeantes da violência, segundo avaliação das famílias, 58\% acreditam que os conflitos do casal contribuíram para desencadear a violência, $51 \%$ acreditam que foram as características próprias da criança ou adolescente, $49 \%$ atribuem ao histórico de vida dos pais, $40 \%$ associam a violência ao fato de ter dificuldades em colocar limites para seus filhos, $32 \%$ afirmam que o alcoolismo foi um dos fatores desencadeantes, $25 \%$ fatores socioculturais, $25 \%$ falta ou excesso de trabalho, $21 \%$ outros fatores e $9 \%$ outros tipos de drogas.

A superação dos fatores desencadeantes, após a intervenção dos profissionais do CRAMI, pode ser observada a seguir. Entre as pessoas que atribuíram o desencadeamento da violência aos conflitos entre o casal, $61 \%$ acreditam que esse fator foi superado. Dentre aquelas que associam o desencadeamento da violência às características da criança e ou adolescente, $58 \%$ acreditam na superação. Com relação ao fator alcoolismo, 29\% afirmam que houve êxito na superação. Quanto àquelas que apontaram o histórico de vida como fator desenca- deante, $20 \%$ afirmam que houve superação. Os fatores socioculturais foram superados por $9 \%$ e as dificuldades em colocar limites por $7 \%$ das famílias.

Com relação ao acompanhamento proposto pelo CRAMI, pode-se observar que a participação de cada integrante da família variou na freqüência e forma de atendimento. O total de mães, agressoras ou não, que aderiram a uma ou outra forma de acompanhamento, foi de $92 \%$; os pais, agressores ou não, aderiram em $39 \%$ e a criança e/ou adolescente vitimizado, em 73\%. Quando se considerou a variável reside com a criança, observou-se que a porcentagem de pais que tiveram alguma forma de atendimento sobe para $74 \%$, enquanto que a da mãe permanece em $92 \%$.

A participação do pai e da mãe também apresenta variação, quando considerou a condição dos mesmos serem os agressores. Quando o pai é agressor, sua adesão a alguma forma de acompanhamento ocorre em $58 \%$ dos casos e, quando a mãe é agressora, a adesão é de $100 \%$. Considerando o casal, pai e mãe, o acompanhamento realizado por visitas domiciliares foi o que recebeu maior adesão, envolvendo $47,5 \%$ dos pais agressores e $68 \%$ das mães nessa condição. Com relação às crianças e/ou adolescentes vitimizados, a psicoterapia foi a forma de maior adesão, representando $28 \%$ dos casos.

No gráfico 1 observa-se que 80\% das famílias avaliaram que a intervenção do CRAMI colaborou para diminuir ou interromper o padrão abusivo no relacionamento intrafamiliar.

\section{Discussão}

Na sociedade brasileira atual, o uso da punição física é ainda um instrumento bastante freqüente na educação dos filhos. Os pais tendem a defender essa forma de disciplina que, em determinadas circunstâncias, pode favorecer a banalização e a cronicidade da violência física doméstica contra crianças e adolescentes. Observamos que para alguns pais, inclusive alguns profissionais, tais atos por não serem considerados práticas abusivas serão reproduzidos como uma prática normal de disciplinamento (Azevedo \& Guerra, 1994). De acordo com alguns relatórios de atividades do CRAMI, essa é a modalidade de violência mais notificada, sendo que de 1988 a 2000 representou $51 \%$ do total de notificações (Relatório de Atividades, 
Tabela 1

Distribuição das modalidades de violência cometidas pelos pais.

\begin{tabular}{lcc}
\hline Modalidades de violência & Mãe \% & Pai \% \\
\hline Violência física & 23 & 5,5 \\
Violência sexual & - & 10 \\
Negligência & 27 & 5,5 \\
Violência psicológica & 4,5 & 5,5 \\
Violência física + psicológica & 23 & 26 \\
Violência física + sexual & - & 15,5 \\
Violência física + negligência & 13,5 & 16 \\
Violência sexual + psicológica & - & 5,5 \\
Violência sexual + negligência & - & 5,5 \\
Negligência + violência psicológica & 4,5 & - \\
Violência física + sexual + psicológica & - & 5,5 \\
Violência física + negligência + violência psicológica & 4,5 & -
\end{tabular}

Gráfico 1

Avaliação das famílias relativa à intensidade da violência após a intervenção do CRAMI.

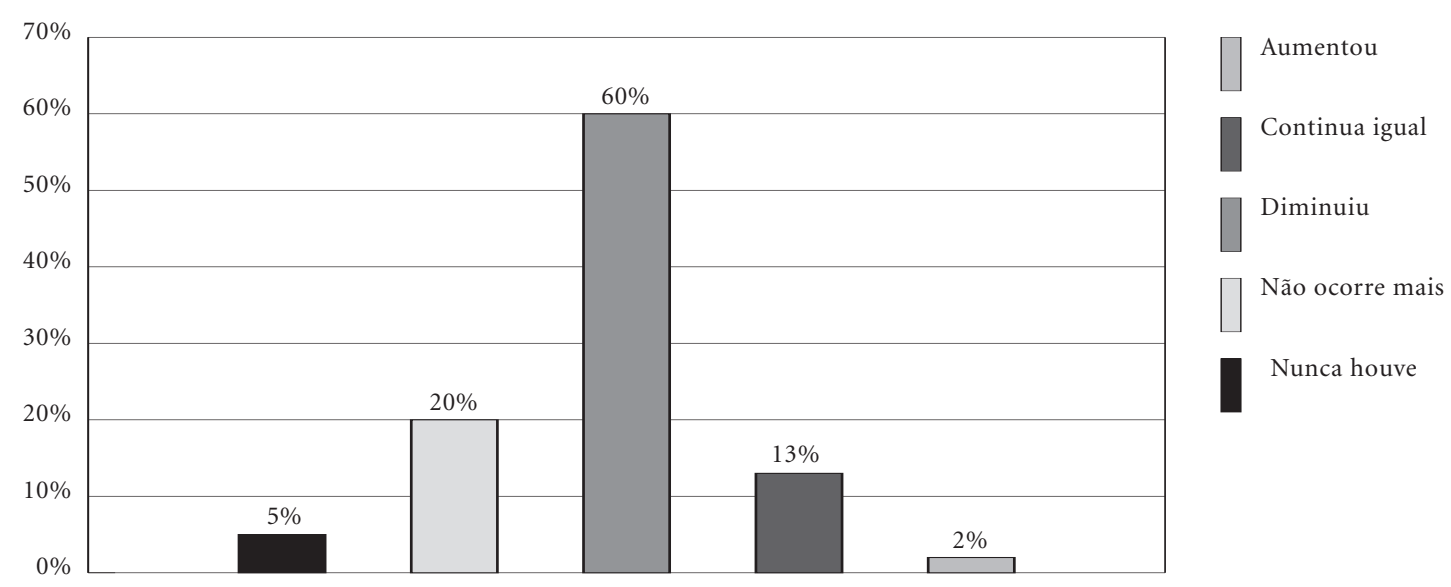

2000). Esta pesquisa confirma a tendência, uma vez que a violência física está presente em $58 \%$ das famílias participantes. Um aspecto que pode justificar o alto índice de notificação dessa modalidade de violência é o fato de que ela pode deixar marcas visíveis no corpo da criança, facilitando sua identificação, o que não ocorre quando a modalidade de violência cometida é, por exemplo, a psicológica. Tanto que na forma pura, essa última é pouco identifica$\mathrm{da}$, aparecendo com maior freqüência quando associada a outras formas de violência.
Neste estudo, a violência sexual apresenta uma freqüência maior do que a descrita em outras pesquisas e até mesmo em dados anteriores do CRAMI (Relatório de Atividades, 2000). Como as famílias não são mais notificadas diretamente ao CRAMI, o que ocorreu até 1998, e sim encaminhadas pelos órgãos de proteção, é possível supor que exista uma preocupação desses órgãos em priorizar o atendimento das situações que envolvem violência sexual. Outra possibilidade é que esteja ocorrendo maior conscientização com relação a esse fenômeno, o que, 
conseqüentemente, desperta o interesse em buscar formas de tratamento que atendam a essa demanda. Com relação ao sexo das crianças vitimizadas, em geral é a menina quem mais sofre violência, o que também foi observado em pesquisas sobre o tema (Saffioti, 1997; Azevedo \& Guerra, 1994; Santos, 1991). Proporcionalmente, a violência sexual foi a modalidade em que a menina, quando comparada ao menino, mais sofre violência, fato esse observado por outros autores (Saffioti, 1997; Santos, 1991; Guerra, 1985). A negligência é a única modalidade de violência em que os meninos apresentam maior índice do que as meninas.

Quando se observa a situação da mãe na família, percebe-se que a sua participação na organização familiar é muito importante. É ela quem está mais próxima fisicamente da criança, seja responsabilizando-se pelo cuidado afetivo e educacional dos filhos, seja garantindo sua sobrevivência, já que, na maioria das vezes, quando o casal está separado, é com ela que a criança permanece. Essa proximidade parece favorecer a ocorrência de situações de violência, porque a mãe é apontada nessa pesquisa como aquela que mais agride os filhos no ambiente doméstico. O pai também aparece como um dos principais agressores e a diferença entre o número de notificações em que aparece como agressor e aquele em que a mãe é agressora é pequena. No entanto, quando é observada a aplicação das medidas de proteção, percebe-se que elas ocorrem em maior número nas situações em que o pai é agressor do que naquelas em que a mãe é agressora, aventando a possibilidade de que a violência praticada pelo pai tende a ser mais intensa do que a praticada pela mãe.

Existe uma variação de freqüência e de modalidades de violência cometidas pelo pai e pela mãe. A negligência, na forma pura, aparece mais associada à mãe e dirigida aos filhos homens. Ao contrário, a violência sexual é, na maioria das vezes, cometida pelo pai e dirigida às filhas. Esse dado pode refletir a forma como a questão de gênero se revela no espaço doméstico.

Com relação ao tratamento proposto às famílias, nas situações em que o pai ou a mãe é o agressor, foi observada a adesão das mães supe- rior a dos pais. O que reforça a hipótese, já sugerida anteriormente, de que o envolvimento das mães com os filhos e com os problemas familiares apresenta uma qualidade diferente da dos pais.

O acompanhamento por visitas domiciliares é a forma de tratamento mais freqüente entre os adultos da família. Já com relação às crianças e adolescentes vitimizados, a forma de tratamento que prevalece é o acompanhamento psicoterápico. Esses aspectos parecem estar associados à dificuldade que as famílias, principalmente os pais, têm de reconhecer a necessidade de ajuda profissional e, em uma parcela significativa, em aceitar alguma forma de intervenção. Ao mesmo tempo, o fato de as crianças serem aquelas que mais aderem ao tratamento psicoterápico faz refletir sobre alguns pressupostos teóricos na psicologia. Estes fundamentam-se no entendimento acerca das fantasias inconscientes dos pais à procura de alguém que conserte seu filho ou o filho como "representante do conflito familiar", expressando dessa forma, além das dificuldades pessoais em buscar/aceitar ajuda, também os limites de alcance que foi encontrado nesta proposta.

A abordagem em que se estabeleceu a proposta de trabalho fundamenta-se na compreensão de que a violência doméstica contra a criança e o adolescente é um "sintoma" modulado por dificuldades culturais, sociais, econômicas e das relações interpessoais, provocando conflitos nas relações familiares, devendo, os cuidados serem extensivos a todo grupo familiar.

Considerando que $80 \%$ das famílias participantes desta pesquisa referiram que o comportamento abusivo dos adultos em relação às crianças e adolescentes diminuiu ou não ocorre mais, pode-se inferir que a oportunidade de refletir sobre as dificuldades e dúvidas nos relacionamentos interpessoais, assim como formas de educar e colocar limite, foi capaz de provocar modificações no contexto das relações afetivas familiares. Dessa forma as famílias puderam encontrar novas possibilidades para conduzir a supervisão e os cuidados necessários para o amplo desenvolvimento das capacidades que toda criança e adolescente são providos, e que têm direito. 


\section{Colaboradores}

AMM Brito, DMT Zanetta, RCV Mendonça, SZP Barison e VAG Andrade participaram igualmente da concepção da pesquisa, da elaboração do instrumental de pesquisa (questionário), da entrevista com as famílias para aplicação do questionário, do tratamento dos dados, do estudo, análise e interpretação dos dados, da redação e revisão crítica do texto. Todas as pessoas que fizeram contribuições substanciais para o artigo, mas não preencheram os critérios de autoria, são citados no agradecimento

\section{Agradecimentos}

A Gislaine Cristina Rastelli pela contribuição na aplicação dos questionários na fase inicial desta pesquisa. Ao CRAMI, em especial, pelo apoio e recursos materiais. Às famílias que participaram desta pesquisa pela disponibilidade em nos atender e consentir a divulgação dos dados.

\section{Referências bibliográficas}

Azevedo MA \& Guerra VNA 1994. Ousar assumir. Guia prático para se posicionar frente ao fenômeno, p. 18. In Módulo $2 \mathrm{~A} / \mathrm{B}$ do telecurso de especialização em violência doméstica contra crianças e adolescentes. CRI/ IPUSP/USP, São Paulo.

Azevedo MA \& Guerra VNA 1988. Pele de asno não é só história...Um estudo sobre a vitimização sexual de crianças e adolescentes. Editora Roca, São Paulo.

Azevedo MA \& Guerra VNA 1989. Vitimação e vitimização: questões conceituais, pp. 25-47. In MA Azevedo \& VNA Guerra (orgs). Crianças vitimizadas: a síndrome do pequeno poder. Iglu, São Paulo.

Azevedo MA 1995. Violência doméstica contra crianças e adolescentes: compreensão do fenômeno no Brasil, pp. 1-19. In Anais da I Jornada Internacional sobre a Infância e Violência Doméstica/Proteção e prevenção. Laboratório da Criança LACRI/IPUSP, São Paulo.

Brasil 1990.Lei no 8.069. Estatuto da Criança e do Adolescente.

CRAMI (Centro Regional de Atenção aos Maus-tratos na Infância) 2000. Relatório de Atividades. São José do Rio Preto.

Guerra VNA 1985. Violência de pais contra filhos: procurase as vítimas. Editora Cortez, São Paulo.

Lei Estadual no 10.498 2000. Obrigatoriedade de notificação compulsória de maus-tratos em crianças e adolescentes, vol. 110 - no 4. Diário Oficial da União, Brasília.
Marques MA 1986. Um estudo preliminar sobre a violência doméstica contra a criança numa favela do Rio de Janeiro. Dissertação de mestrado. Columbia University. (Mimeo)

Minayo MCS 1994. A violência social sob perspectiva da saúde pública. Cadernos de Saúde Pública 10(1):7-18.

Minayo MCS (coord.) 1993. Prevenir e proteger: análise de um serviço de atenção à criança vítima de violência doméstica. ENSP-Fiocruz-Claves, Rio de Janeiro.

MS (Ministério da Saúde) 2001. Portaria do Ministro de Estado da Saúde no 1.968/737 MS/GM. Diário Oficial da União no 96, Brasília.

MS (Ministério da Saúde) 2002. Notificação de maus-tratos contra crianças e adolescentes pelos profissionais de saúde: um passo a mais na cidadania em saúde. Ministério da Saúde/Secretaria de Assistência a Saúde, 48p.: série A Normas e Manuais Técnicos; no 167. Brasília.

Saffioti HIB 1997. No fio da navalha: violência contra crianças e adolescentes no Brasil atual, pp. 56-64. In FR Madeira (org.). Quem mandou nascer mulher? Estudos sobre crianças e adolescentes pobres no Brasil. Editora Record-Rosa dos Tempos, Rio de Janeiro.

Santos HO 1987. Crianças espancadas. Editora Papirus, Campinas

Santos HO 1991. Crianças violadas. CBIA-CRAMI, Brasília.

Artigo apresentado em 5/12/2003

Aprovado em 11/10/2004

Versão final apresentada em 3/12/2004 